\title{
Pig-to-Nonhuman Primates Pancreatic Islet Xenotransplantation: An Overview
}

\author{
Marco Marigliano • Suzanne Bertera • Maria Grupillo • \\ Massimo Trucco • Rita Bottino
}

Published online: 2 August 2011

(C) The Author(s) 2011. This article is published with open access at Springerlink.com

\begin{abstract}
The therapy of type 1 diabetes is an open challenging problem. The restoration of normoglycemia and insulin independence in immunosuppressed type 1 diabetic recipients of islet allotransplantation has shown the potential of a cell-based diabetes therapy. Even if successful, this approach poses a problem of scarce tissue supply. Xenotransplantation can be the answer to this limited donor availability and, among possible candidate tissues for xenotransplantation, porcine islets are the closest to a future clinical application. Xenotransplantation, with pigs as donors, offers the possibility of using healthy, living, and genetically modified islets from pathogen-free animals available in unlimited number of islets. Several studies in the pig-to-nonhuman primate model demonstrated the feasibility of successful preclinical islet xenotransplantation and have provided insights into the critical events and possible mechanisms of immune recognition and rejection of xenogeneic islet grafts. Particularly promising results in the achievement of prolonged insulin independence were obtained with newly developed, genetically modified pigs
\end{abstract}

M. Marigliano $\cdot$ S. Bertera $\cdot$ M. Grupillo $\cdot$ M. Trucco $\cdot$

R. Bottino $(\bowtie)$

Division of Immunogenetics, Department of Pediatrics, Rangos Research Center, Children's Hospital of Pittsburgh, 6th floor, Room 6126, 4401 Penn Avenue,

Pittsburgh, PA 15224, USA

e-mail: rib16@pitt.edu

M. Marigliano

Regional Center for Diabetes in Children and Adolescents,

Salesi's Hospital,

Via Corridoni 11,

60123 Ancona, Italy

M. Grupillo

RiMeD Foundation,

Palermo, Italy islets able to produce immunoregulatory products, using different implantation sites, and new immunotherapeutic strategies. Nonetheless, further efforts are needed to generate additional safety and efficacy data in nonhuman primate models to safely translate these findings into the clinic.

Keywords Type 1 diabetes - Islet xenotransplantation . Pancreas $\cdot$ Non-human primates $\cdot \beta$-cell replacement

\section{Introduction}

In the year 2000 the Edmonton protocol proved that clinical pancreatic islet allotransplantation (alloTx) can be successfully performed to treat type 1 diabetes (T1D) using a steroid-free immunosuppressive regimen [1]. Even if islet replacement could be considered a preferable alternative to insulin therapy in long-term diabetic patients, this therapeutic option will be practically limited by the number of islet donors that will never be sufficient. A possible solution to the problem of tissue supply may be found by investigating the potential of embryonic as well as induced pluripotent stem cells to generate functional insulinproducing cells. Clinical applications await successful testing in animal models. Alternatively, xenotransplantation (xenoTx) of pig islets is currently the most advanced and appealing approach with respect to a possible clinical application [2]. Pigs are the best candidates as human substitutes [3] for several reasons: pig insulin differs from human insulin by just one amino acid; pig islets have lower sensitivity to destruction by recurrent T1D autoimmunity than human islets [4], they do not accumulate amyloid [5], and pig donors can be genetically modified to improve immunomodulation and cytoprotection of pig islets. The 
experimental results of pig islets to non-human diabetic primates xenoTx are more encouraging than those obtained using pig whole organs, which makes their employment predictable in clinical trials in the next few years $[6 \bullet \bullet]$. To make this technique a clinically feasible treatment option we need to generate more convincing preclinical data in the pig-to-primate xenoTx model.

\section{Rationale for Pig Islet XenoTx}

Clinical human islet transplantation is emerging as a suitable therapeutic option in T1D patients with uncontrollable glycemic management limited by hypoglycemia unawareness and effective hormonal counter-regulation [7, 8]. Improving the islet processing techniques and introducing new immunomodulatory strategies, we expect to increase the benefit/risk ratio of human islet alloTx. However, the discrepancy between the number of potential islet recipients (ie, patients with T1D with frequent episodes of severe hypoglycemia and those with devastating microvascular diabetes complications) [9] and the number of available donors remains the major crucial issue to be solved, before a broader use of islet transplantation might become a reliable clinical alternative [1].

Pig islet xenoTx currently represents a very promising solution to the limited donor supply [10]. It is important to underline that pig islets might have different additional distinct advantages over human islets for this purpose. First, the quality of prepared pig islets from a pig donor is consistently higher than human islets from a deceased donor (no comorbidity, senescence, brain death, and cold ischemia injury). Second, porcine islet xenografts may be resistant to destruction by recurrent autoimmunity [11]. Third, the risk of infectious disease transmission associated with xenoTx of pancreatic islets is lower than the one observed in human islet alloTx. Furthermore, it is possible to induce donor-specific immunologic hyporesponsiveness pretreating the recipient with donor antigen(s) [12] or using genetically modified pig islets with the overexpression of genes encoding cytoprotective and immunomodulatory molecules [13].

\section{Pig Islet Source, Isolation, and Preparation}

In human islet alloTx, an average of 10,000 human islet equivalents (IEQ) $/ \mathrm{kg}$ of recipient body weight are considered necessary to achieve insulin independence [1]. There is not a consensus for their minimal number in xenoTx [14]. Different groups have proposed islet numbers in the range of 25,000 to $85,000 \mathrm{IEQ} / \mathrm{kg}$ of body weight as the requirement to achieve blood glucose normalization in diabetic non-human primates (NHPs) with either neonate or adult pig islets $[15 \cdot, 16,17]$. Pig fetal or neonatal islet-like clusters are easy to isolate, but require a period of several weeks to mature into glucose-sensing and insulin-producing cells [18]. The immature cells are more resistant to inflammation and ischemia, and endure the engraftment process better than adult islets. The major advantage of the islet transplantation using islets isolated from adult pigs [18] is that graft function can be achieved and monitored immediately after transplantation.

\section{Fetal Islets}

The isolation of fetal islets requires relatively easy techniques [19]. Because of the limited amount of exocrine tissue, isolation can be completed just using a simple mixture of exogenous digestive enzymes. Pure islet-like cell clusters (ICCs), also called proislets, can be obtained by simple culture without any technical purification step [19]. However, even if ICCs can normalize blood glucose levels in rodents, several studies have shown that ICCs have poor insulin response to glucose for relatively long periods [20]. Fetal islets are more resistant to ischemic injuries consequent to pancreas procurement, probably due to the relative lack of exocrine tissue retained within ICCs and also for other various characteristics typical of fetal tissue itself [19]. Putative precursor cells, located in the pancreatic ducts or among the ICCs, allow for proliferation after transplantation. Even fetal porcine pancreas fragments have the potential to grow, mature, and function normally when transplanted in a neovascularized site [21].

As previously mentioned, perhaps the major disadvantage of fetal islets is their immaturity, which is associated with delayed functionality: it may take over 2 months before achieving blood glucose normalization in in vivo transplantation experiments [22] and, during this period, there is a poor insulin response to glucose. A second disadvantage is the high expression of $\alpha-1,3$-galactose (Gal) on the surface of the fetal pig islets - the sugar responsible for hyperacute rejection-which renders those islets more susceptible to rejection than adult pig islets, which, in contrast, express little Gal [23]. Due to the size of the fetal pancreas, only relatively small numbers of ICCs can be obtained, posing an ethical problem on how many fetuses may be necessary to normalize glycemia in diabetic NHPs, let alone humans. Unless better ways to increase the $\beta$-cell numbers in vitro become available, it is necessary to use tens of pig fetuses to restore normoglycemia in a patient.

\section{Neonatal Islets}

Neonatal pig islets (NPIs) (ie, islets obtained from piglets aged 1-5 days) can be easily procured and isolated by enzymatic digestion [24]; freshly isolated NPIs consist only 
of $7 \%$ endocrine cells, and $11 \%$ epithelial cells, whereas exocrine cells represents approximately $74 \%$ of the cell pool. During in vitro culture, however, acinar cells undergo apoptosis leading to enrichment of the endocrine component ( $35 \%$ after 9 days of culture) and of the pool of nongranulated epithelial cells [24]. During in vitro culture NPIs, and more specifically $\beta$ cells, proliferate, as indicated by studies of bromodeoxyuridine (BrdU) incorporation over time [25]. Interestingly, BrdU incorporation shows two higher peaks: initially after isolation and around days 9 to 12 , when the cell cluster assume an islet-like morphology [25]. Neonatal pig $\beta$ cells are more responsive to glucose than fetal pig $\beta$ cells are [24] but yet not as fully functional as adult cells. The process of maturation of the secretory machinery in neonatal pancreatic islets involves cell-to-cell contact, expression of gap and adherence junctional proteins, and can be accelerated by prolactin [26]. After transplantation in immunodeficient mice the $\beta$-cell mass of NPIs increases up to 20 times further, confirming that $\beta$ cells proliferate and/or that epithelial precursor cells differentiate into $\beta$ cells [24]. Although insulin secretion is also delayed after transplantation, the maturation period is generally shorter than after fetal islet transplantation.

NPIs express xenoantigens, such as human-serum stained epitopes and IB4 (eg, Gal) epitopes but also other undefined xenoantigens [25], with potential relevance for possible clinical improved treatments. The availability of $\alpha$ 1,3-Gal knockout (GT-KO) pigs as a source of neonatal islet cells can therefore prove useful to attenuate, although not completely abrogate, the problem of hyperacute rejection.

Neonatal islets from 1- to 5-day-old piglets do not differ substantially from 1-month-old piglet islets, showing a similar response to glucose stimulation in vitro during incubation, as well as comparable $\beta$-cell mass and function, and can therefore be considered a valid alternative source of islets to adult ones.

The advantage of using neonatal over fetal pig islets consists of the possibility of preventing the sow from undergoing surgery necessary for the fetus harvesting. The number of ICCs isolated from the neonatal pig pancreas is not significantly different than that of fetal ICCs, leaving yet unresolved the problem of supply, thus the need for numerous neonatal pigs to treat an NHP or a patient.

\section{Adult Islets}

In contrast to fetal and neonatal islets, adult porcine islets (pig donor age $>6$ months), due to their mature status, start functioning immediately following isolation and transplantation [27]. Their immunogenicity, despite a low expression of Gal, is highly variable and the technique for their isolation rather difficult. The isolation outcome varies and the effects/damage of isolation can influence their func- tional performance following transplantation [28]. In adult pigs, the peri-insular matrix is poorly developed; this makes islets susceptible to fragmentation and, consequently, cell breakage during the isolation process. Generally, retired breeders (sows that underwent multiple pregnancies) are preferred as pancreas donors, providing islets with a more compact shape and more resistant to isolation and culture. One adult pig pancreas can provide a sufficient quantity of functional islets to perform xenoTx in one or two NHPs. In contrast to fetal and neonatal islets, $\beta$ cells from adult pigs are able to respond to hyperglycemia within hours after transplantation. However, several studies reported low insulin secretion even from isolated adult pig islets [18, 29]. The poor insulin secretion of isolated pig islets in vitro, however, does not necessarily imply a lack of function in vivo. Published data show that both isolated neonatal and adult pig islets have been able to correct diabetes in NHPs $[15 \cdot, 16,17]$.

\section{Isolation and Preparation}

Pancreata are recovered during a non-survival surgical procedure. Concerning fetuses and neonates pancreatic organs, these are dissected immediately after exsanguination and euthanasia of the piglet. Retained blood in the tissue reduces islet yield, possibly because of inhibition of the collagenolytic activities of the digestive enzymes; for this reason, extensive flushing of the organ before, during, and directly after pancreatectomy is necessary. In adult pigs the pancreas is harvested with a technique similar to the one utilized to harvest the pancreas from deceased organ donors [30]. Islet viability is strongly influenced by warm and cold ischemia time, the isolation process, and the period of storage, but it is difficult to evaluate the exact influence of each factor [26, 31]. Warm ischemia must be kept as minimal as possible to avoid autolysis of the pancreas by proteolytic and lipolytic enzymes [31]. In adult pancreata, intraductal injection with collagenase solution early after pancreas dissection (before its cold preservation) seems to contribute to a higher islet yield; however, collagenase is commonly injected intraductally after cold preservation, just before the isolation begins [31].

Since the introduction of an efficient method for the bulk isolation of pig pancreatic islets by Ricordi et al. [18], most groups use a similar, semiautomatic isolation method also for pig islets. The pancreas, following collagenase injection, is mechanically disrupted in a digestive chamber under controlled temperature [26]. Continuous exposure of the tissue to digestive enzymes is necessary, but it is important to avoid overexposure and damage to the islets. The enzymatic/mechanical digestion is followed by a purification step, thus the separation of the porcine islets from the exocrine tissue. The standard method for islet purification is 
based on a density-gradient centrifugation, taking advantage of the fact that islets have a lower density than exocrine tissue. Usually a purity of $70 \%$ to $90 \%$ (islets/ whole tissue) is efficiently obtained with various, equally valid, gradient types [31]. For fetal and neonatal islets a culture time of several days is required to facilitate cell re-aggregation and to eliminate the exocrine cells [32]. However, adult pig islets seem to be more fragile than fetal and neonatal ICCs during culture, and loss of islet mass and viability are observed over time. Short-term culture is therefore desirable for adult islets. Typical functional assays to assess the functionality of the isolated islets include in vitro glucose-stimulated insulin release tests, and in vivo function determined by transplanting islets into small diabetic, immunodeficient rodents, such as nonobese diabetic/scid mice [31].

\section{Induction of Diabetes in NHPs}

Studies in the pig-to-NHPs islet xenoTx model are needed to provide evidence of safety and efficacy prior to clinical phase 1 and 2 trials. To meet these criteria, preclinical studies should be performed in diabetic NHPs; to obtain these, three different approaches have been used. Spontaneous diabetes, reported in several strains of monkeys including cynomolgus, is usually associated with age, obesity, $\beta$-cell degeneration, and extensive amyloid deposition [33]; the availability of these monkeys is limited, and their diabetes could not be considered as a faithful T1D model. Surgical pancreatectomy is a second option, but its execution is difficult and it has associated morbidity problems. This technique is probably the most convincing in the generation of irreversible diabetes, but pancreatectomy needs to be total to avoid potential residual function and possibly $\beta$-cell regeneration, and it has the disadvantage of eliminating the endogenous exocrine pancreatic function. The third approach currently used is chemical induction of hyperglycemia through streptozotocin (STZ) [34]. STZ is a compound derived from the bacterium Streptomyces achromogenes with the ability to selectively destroy $\beta$ cells by DNA damage and nicotinamide adenine dinucleotide depletion [34]. Its intravenous administration successfully achieves killing of $\beta$ cells and subsequent induction of hyperglycemia, but a discussion on the optimal dose remains an open problem.

A single dose of $30 \mathrm{mg} / \mathrm{kg}$ of STZ is not sufficient to induce complete diabetes; although larger doses (100$150 \mathrm{mg} / \mathrm{kg}$ ) are, they are also associated with harmful side effects $[11,35]$. Nephrotoxicity and hepatotoxicity are some of the major disadvantages of high-dose STZ; nonetheless, STZ-induced diabetic monkeys usually remain diabetic and insulin dependent for years, with no significant endogenous
C-peptide release even after glucose stimulation and histologic evidence of only a few insulin-staining cells surviving in the pancreas [11]. There is interspecies variation in the effectiveness of STZ also due to the different expression of low-affinity glucose transporter 2 (GLUT-2), which is the receptor through with STZ accesses the $\beta$ cells but also, to a lower extent, renal and hepatic cells, where this receptor is also expressed. STZ could thus cause hepato- and nephrotoxicity.

There are other important variables that can influence the effectiveness of STZ after intravenous administration, such as the age of the NHPs and an intrinsic sensitivity of the $\beta$ cells to the drug [36]. Post-STZ hyperglycemia is typically the main indication that a diabetic status has been established; however, C-peptide levels are usually measured for a correct diagnosis. Primate C-peptide levels less than $0.9 \mathrm{ng} / \mathrm{mL}$ are considered sufficient to indicate a diabetic status; however, our group has established that diabetes is durable when at least a $75 \%$ reduction in C-peptide levels post STZ is recorded $[35,37]$ and a negative response (lack of C-peptide increase) after a challenge is confirmed [4, 37]. The intravenous glucose tolerance and arginine stimulation tests are the most used challenge tests. The diabetic status of NHPs can be further evaluated by checking the variations in hemoglobin $\mathrm{A}_{1 \mathrm{c}}\left(\mathrm{HbA}_{1 \mathrm{c}}\right)$ levels [38]. The effect of STZ on $\beta$ cells can also be evaluated by histologic examination of pancreatic biopsies, but this requires a surgical procedure and, because some residual insulin immunostaining is always present, it is difficult to quantify the real extent of the damage. The combination of hyperglycemia, insulin dependence, failure to increase Cpeptide levels after stimulation, and increase in $\mathrm{HbA}_{1 \mathrm{c}}$ levels allows for a correct diagnosis of STZ-induced diabetes.

\section{Porcine Islets XenoTx Survival in NHPs}

Currently, pig islet xenoTx studies in NHPs have been reported by 15 institutions, including transplantation in nondiabetic (Table 1) [19, 23, 39-43] and diabetic recipients (Table 2) [13], [15•, 16, 17, 38, 39, 42, 44-48]. However, prolonged restoration ( $>3$ months) of insulin independence after porcine islet xenoTx in NHPs with spontaneous, chemical, or surgically induced diabetes has only been reported by a few groups [16, 17, 46-48], with xenograft survival exceeding 6 months in even fewer cases. These promising findings indicate that pig islet xenoTx has the potential to cure diabetes in NHPs, and provide a strong rationale to envision clinical future applications.

Long-term insulin independence has been achieved using different strategies, such as: 1) intraportal infusion of wild-type adult and neonatal pigs islet in immunosup- 
Table 1 Pig islet cell xenografts in nondiabetic nonhuman primates

\begin{tabular}{|c|c|c|c|c|c|}
\hline $\begin{array}{l}\text { Donor } \\
\text { pig age }\end{array}$ & Recipient & $\begin{array}{l}\text { Site of } \\
\text { transplantation }\end{array}$ & $\begin{array}{l}\text { Immunosuppression, encapsulation, } \\
\text { and/or genetic engineering }\end{array}$ & $\begin{array}{l}\text { Maximum } \\
\text { graft survival }\end{array}$ & Reference \\
\hline Adult & Cyno $(n=8)$ & Intraportal & None $(n=7)$ Pretreatment with sCR1 $(n=1)$ & $\begin{array}{l}\text { Post-transplant follow-up } \\
\text { for } 60 \text { min only }\end{array}$ & Bennet et al. [23] \\
\hline Adult & Baboon $(n=2)$ & Intraportal & $\begin{array}{l}\text { Whole-body and thymic irradiation }+ \text { ATG }+ \\
\text { EIA }+ \text { MMF }+ \text { CsA }+ \text { CVF }+ \text { steroids }+\alpha \text { CD } 154\end{array}$ & $>14 \mathrm{~d}$ and $<28 \mathrm{~d}$ & Buhler et al. [39] \\
\hline \multirow[t]{2}{*}{ Adult } & Baboon $(n=4)$ & Intraportal & $\mathrm{ATG}+\mathrm{CsA}$ or $\mathrm{LF}-195+\mathrm{MMF}+$ steroids & $2 \mathrm{~d}$ & $\begin{array}{l}\text { Cantarovich } \\
\text { et al. [40] }\end{array}$ \\
\hline & Cyno $(n=1)$ & & & & \\
\hline \multirow[t]{5}{*}{ Adult } & Group 1 & $\begin{array}{l}\text { Renal subcapsular } \\
\text { and intraportal }\end{array}$ & $\begin{array}{l}\text { Group 1: (cyno) } \mathrm{CP}+\mathrm{CsA}+\text { steroids } \\
\text { (rhesus) } \mathrm{ATG}+\alpha-\mathrm{IL}-2 \mathrm{R}+\mathrm{Cs} \text {; steroids }\end{array}$ & Group 1: $11 \mathrm{~d}$ & $\begin{array}{l}\text { Rijkelijkhuizen } \\
\text { et al. [41] }\end{array}$ \\
\hline & Cyno $(n=4)$ & & & & \\
\hline & Rhesus $(n=4)$ & & & & \\
\hline & Group 2 & & Group 2: $\mathrm{ATG}+\alpha-\mathrm{IL}-2 \mathrm{R}+\mathrm{CsA}$; steroids & Group 2: $53 \mathrm{~d}$ & \\
\hline & Rhesus $(n=4)$ & & & & \\
\hline Adult & Rhesus $(\mathrm{n}=2)$ & Intraportal & None & $>3 \mathrm{~d}$ & $\begin{array}{l}\text { Kirchhof et al. } \\
\text { [42] }\end{array}$ \\
\hline \multirow[t]{3}{*}{ Adult } & Cyno $(n=15)$ & Renal subcapsular & Group $1(n=12)$ : encapsulation & Group 1: $<180 \mathrm{~d}$ & $\begin{array}{l}\text { Dufrane et al. } \\
\text { [43] }\end{array}$ \\
\hline & & & Group 2 ( $n=2)$ : no encapsulation & Groups $2 \& 3:<7 \mathrm{~d}$ & \\
\hline & & & Group $3(n=1)$ : empty capsule & & \\
\hline \multirow[t]{2}{*}{ Fetal } & Cyno $(n=5)$ & Renal subcapsular & Group 1: no immunosuppression & Group 1: $<7 \mathrm{~d}$ & Mandel [19] \\
\hline & & & Group 2: $\mathrm{CsA}+$ steroids $+\mathrm{CP}$ or $\mathrm{BQR}$ & Group 2: $>40 \mathrm{~d}$ & \\
\hline
\end{tabular}

Effects of donor pig age, recipient species, and immunotherapeutic strategy on maximum islet xenograft survival.

$\alpha-I L-2 R$ anti-interleukin 2 receptor antibody; $A T G$ anti-thymocyte globulin; $B Q R$ brequinar; $C P$ cyclophosphamide; $C s A$ cyclosporin A; $C V F$ cobra venom factor; Cyno cynomolgus; EIA extracorporeal immunoadsorption; LF-195 deoxyspergualin analogue; MMF mycophenolate mofetil; $s C R 1$ soluble complement receptor $1 ; d$ days.

pressed diabetic NHPs [15•, 17]; 2) intraportal infusion of islets from adult $\alpha-1,3$-Gal-deficient animals transgenic for human membrane cofactor protein (CD46) in STZ-diabetic immunosuppressed NHPs [15•, 46]; 3) implantation of embryonic pig pancreatic precursor tissue in STZ-diabetic animals [48]; 4) intraperitoneal transplantation of microencapsulated adult pig islets in nonimmunosuppressed spontaneously diabetic NHPs; and 5) subcutaneous implantation of a monolayer of encapsulated adult islets on a collagen matrix in a nonimmunosuppressed NHP [48, $49 \cdot \bullet$. The choice of the anatomical site for the implantation of porcine islets in the recipient is a crucial aspect in xenoTx. The current clinical practice is to put islets into the liver, through the portal vein. However, it has now been recognized that this implantation site has several characteristics that can hamper islet engraftment and survival, such as low oxygen tension, an active innate immune system, and induction of a strong inflammatory response (the immediate blood-mediated inflammatory reaction [IBMIR]) [50] and that is therefore associated with considerable early graft loss. When placed under the renal capsule, islets are more protected from immediate destruction, but ischemic injury can be a major problem in this site. Although it is a very successful site in rodent recipients, unfortunately, low or no porcine (graft) C-peptide production has been reported after subcapsular transplantation of islets in NHPs $[19,43]$.

Porcine islet transplantation in the subcutaneous tissue showed triggering of early inflammatory responses, whereas encapsulated porcine islets in a macrodevice inserted under the skin more successfully controlled diabetes for up to 6 months, even in the absence of immunosuppression [49••]. In a pig alloTx model, it has been shown that when islets are transplanted into the gastric submucosal space, a site where direct contact with the blood stream is delayed, while a rich arterial blood supply for delivery of oxygen and nutrients is maintained, the graft can survive [30]. This site has several characteristics that could favor islet Tx and islet engraftment: a similar embryonic origin as the pancreas, a delayed direct contact with the blood stream while a rich arterial blood supply for delivery of oxygen and nutrients is maintained, and venous drainage of produced insulin into the portal vein blood stream for direct utilization in the liver; a 


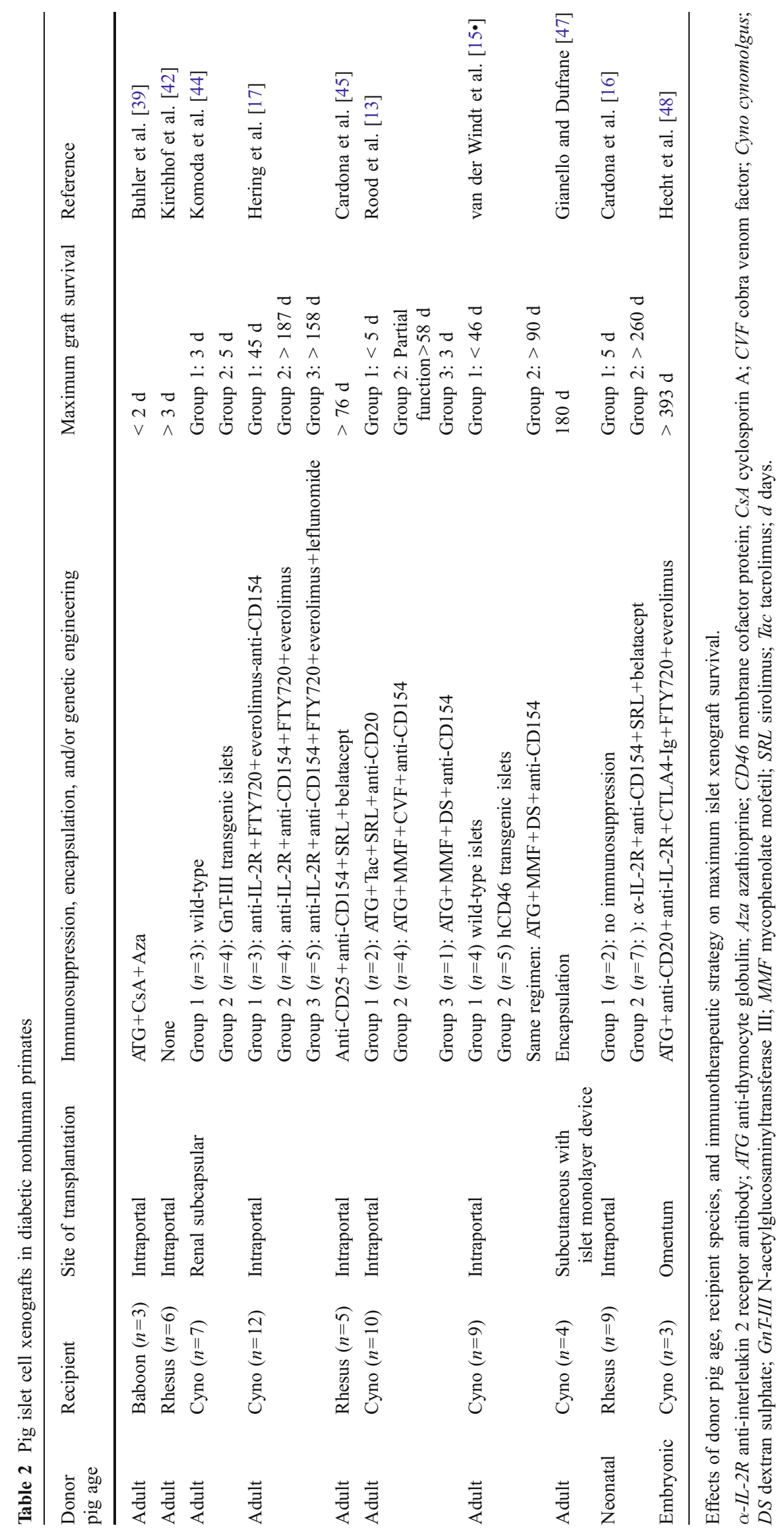


clinical advantage is that transplantation can be performed endoscopically and endoscopic biopsies of the transplanted islets can be carried out.

\section{Immunological Response to Transplanted Islets}

The numerous preclinical studies of pig-to-NHP islet xenoTxs have offered important insights into the immune mechanisms and the pathways involved in causing graft damage. The source of pig islets, the microenvironment at the implantation site, and the immunosuppressive therapy significantly affect engraftment and rejection of xenogeneic islets. Pig islet xenografts, where pig islets were isolated from wild-type pigs, can survive for weeks and months in NHP recipients; this indicates that they do not undergo hyperacute rejection as, instead, it occurs in vascularized organ transplantations. In this study neither increases in Gal-specific IgG or IgM circulating antibody levels nor IgG/IgM with associated C9 deposition on islets were observed [17]. When present, the humoral response is mainly characterized by anti-Gal antibody production. AntiGal antibodies are natural preformed antibodies directed against pig epitopes in humans and old-world monkeys. However, the Gal epitope is expressed only on $5 \%$ of adult islets and on $11 \%$ of NPI cells. The use of GT-KO pigs (in association with the human CD46 transgenes) as pig islet donors did not show a substantial protective effect toward early islet loss, suggesting that perhaps antibody binding to non-Gal antigens would likely be a more potent complement activator $[16,17,23]$. In some studies, considerable $\operatorname{IgM}$ and moderate-to-strong C3, C5, and C9 deposition were present on islet surface 2 to 3 days after xenoTx [39-41]. Rejection of pig islets in NHPs is probably a result of a combination of innate responses, evidenced by macrophage infiltration and antibody- and complement-mediated injury, followed by a major T-cell response.

More potent immunosuppressive regimens have been used to protect wild-type pig islets from rejection [17], whereas the introduction of transgenic pigs expressing graft-protecting factors has been shown to require a less toxic immunosuppressive protocol [15•].

Regarding pig islet infusion into the portal vein of NHP, this is associated with a considerable early graft loss, regardless of immune rejection. This loss is not just due to antibody-mediated complement activation, but it involves the nonspecific response IBMIR [51]. The mechanisms behind early graft loss remain poorly understood; it is in part the result of tissue factor production [52] and expression in the pancreatic cells. Recent data point to a relatively underestimated role for natural antibodies, complement, and coagulation [53], and platelet binding to the islets surface and leukocyte infiltration have been demon- strated. Triggering of numerous and not mutually exclusive pathologic events after contact of islets with xenogeneic blood is certainly the answer; despite the substantial loss of islet mass (estimated up to $60 \%$ to $80 \%$ ) in the early phase post-transplantation due to IBMIR, data suggest that a sufficient islet mass survive, achieving and maintaining normoglycemia for months in NHP recipients.

\section{Future Directions for Pig Islets XenoTx}

Pig islet xenoTx shows important, but not insurmountable limitations, even if recent accomplishments in preclinical pig-to-NHP model hold great promises and may have future implications. Concerning preclinical animal models of islet xenoTx there are some relevant considerations on speciesspecific glucose metabolism. For instance, pigs and humans share blood glucose levels in similar concentrations, whereas nondiabetic monkeys exhibit lower unstimulated blood glucose. Endogenous C-peptide levels in monkeys are in higher ranges than in humans, and substantially higher than in pigs. When porcine islets engraft in diabetic NHPs they need to adapt to the higher metabolic demands of their recipients. This results in new cutoff parameters of glucose metabolism associated with good graft islet function, intermediate between donor and recipient baselines [37]. We may envision that, based on the metabolic differences between humans and monkeys, humans and pigs, porcine islets would perform more efficiently in humans than in monkeys. Nonetheless, to pursue the use of porcine islets in preclinical as well as clinical models it is necessary to modify the immunosuppressive protocols and to evaluate agents that can be substitutes for anti-CD154 antibodies, critical and effective components of major studies $[16,17,46]$ because of their thromboembolic effect. Preliminary studies suggest that antagonistic anti-CD40 monoclonal antibodies could be equally effective when combined with IL-2R antibodies, CD28 antagonists, and sirolimus. Several other immunosuppressant agents are currently under investigation [54].

In the future, immunosuppressive molecules should be selected based on their ability to facilitate negative vaccination systems during the pretransplantation phase by administration of donor antigen to the recipient. The immunological obstacles to xenoTx are significant. A way to reduce the immune response after implantation of pig islet cells in the recipient is the use of transgenic animals. Good results using pigs expressing hCD46 (a human complement-regulatory protein) suggest that protection from complement activation is beneficial to survival of the graft (Fig. 1) [15•]. Furthermore, the inhibition of the Tcell-mediated immune response is a necessary component to prevent rejection following xenoTx. The generation of 
Fig. 1 a, Blood glucose (BG) (solid lines) and exogenous insulin (broken line) profiles in a streptozotocin-diabetic recipient of porcine islet graft (M7273). After porcine xenotransplantation no exogenous insulin is required to maintain BG levels lower than $5 \mathrm{mmol} / \mathrm{L}$ (red line) for 1 year. b, In the same animal, primate C-peptide (solid lines) and pig (graft) C-peptide (broken line) levels confirm, respectively, the diabetic status (primate C-peptide) and the positive effect of the pig islet transplantation (Tx) (pig C-peptide) [15•].
A



B

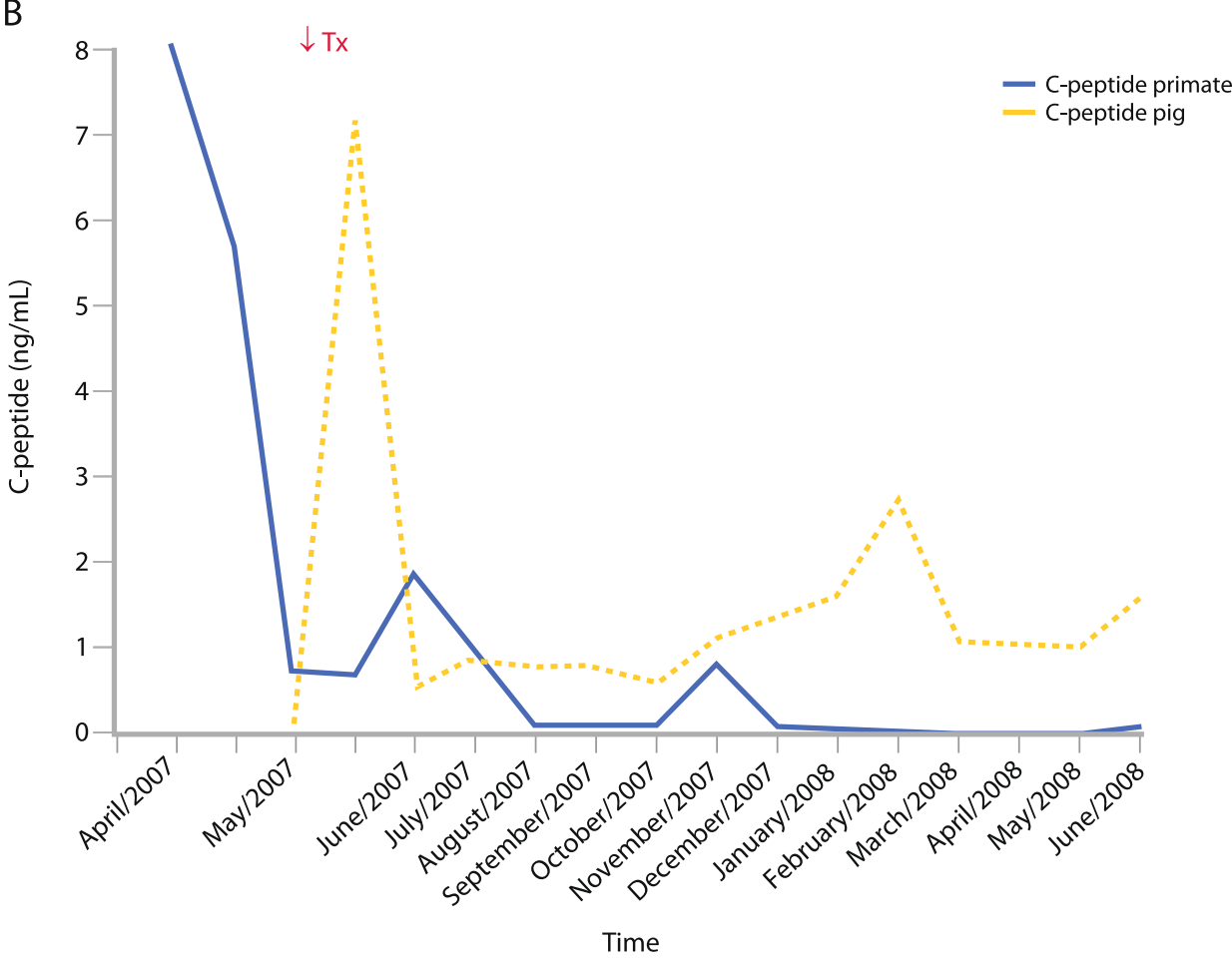

transgenic pigs producing cytotoxic $\mathrm{T}$ lymphocyteassociated antigen (CTLA4) antibodies may also be useful in prolonging graft acceptance [55].

A large number of islet product-directed strategies are currently under investigation to allow minimal immunosuppressive treatment. These include pretransplant islet culture in the presence of mitomycin $\mathrm{C}$ to upregulate transforming growth factor- $\beta$ production of islets [56], surface heparinization, pegylation [57] of islets, and transfection with immunorepellant SDF-1. Alginateencapsulated islets have also been proposed to attenuate antibody and T-cell contact. Optimization of encapsulation protocols may prove to be a successful approach, as promising results indicate $[49 \bullet \bullet, 58]$. All these strategies 
share the central objective of creating an immunoprivileged environment at the islet implantation site. Integrating controlled release of immunoregulatory, cytoprotective, and proangiogenic factors together with the use of bioscaffolds, microspheres and nanoparticles $[58,59]$ could be key to success.

The potential for porcine endogenous retroviruses (PERV) to harm a recipient of pig tissue has been a concern. These potential risks are now considered to be much less significant since activation of PERV can be prevented by small interfering RNA technology [60]. Nevertheless, regulatory requirements will be necessary to monitor and reduce the risk of contracting xenozoonosis in xenoTx.

\section{Conclusions}

Building on the remarkable recent progress in the preclinical pig-to-NHP model, it appears that adult porcine islets have the best potential, from both a logistic and immunologic point of view, to reverse diabetes in NHPs and furthermore in humans. The simultaneous development of suitable sources of genetically modified pigs and more resistant-engineered pig islets, together with the establishment of clinically applicable immunosuppressive regimens, could be translated into tangible benefits for patients with T1D in the very near future. However, questions remain and detailed problems need to be adequately addressed.

Acknowledgment The authors have received a grant from the US Department of Defense.

Disclosure No potential conflicts of interest relevant to this article were reported.

Open Access This article is distributed under the terms of the Creative Commons Attribution Noncommercial License which permits any noncommercial use, distribution, and reproduction in any medium, provided the original author(s) and source are credited.

\section{References}

Papers of particular interest, published recently, have been highlighted as:

- Of importance

•• Of major importance

1. Shapiro AM, Lakey JR, Ryan EA, Korbutt GS, Toth E, Warnock $\mathrm{GL}$, et al. Islet transplantation in seven patients with type 1 diabetes mellitus using a glucocorticoid-free immunosuppressive regimen. N Engl J Med. 2000;343:230-8.

2. Cooper DK, Gollackner B, Knosalla C, Teranishi K. Xenotransplantation-, how far have we come? Transpl Immunol. 2002;9:251-6.
3. Ryan EA, Paty BW, Senior PA, et al. Five-year follow-up after clinical islet transplantation. Diabetes. 2005;54:2060-9.

4. Koulmanda M, Qipo A, Smith RN, Auchincloss Jr H. Pig islet xenografts are resistant to autoimmune destruction by non-obese diabetic recipients after anti-CD4 treatment. Xenotransplantation. 2003;10:178-84.

5. Potter KJ, Abedini A, Marek P, Klimek AM, Butterworth S, et al. Islet amyloid deposition limits the viability of human islet grafts but not porcine islet grafts. Proc Natl Acad Sci USA. 2010;107 (9):4305-10. Epub 2010 Feb 16.

6. •- Hering BJ, Cooper DKC, Cozzi E. Schuurman H-J, Korbutt GS, Denner J, et al. The International Xenotransplantation Association consensus statement on conditions for undertaking clinical trials of porcine islet products in type 1 diabetesExecutive summary. Xenotransplantation. 2009;16:196-202. This paper shows a current consensus statement on islet xenoTx and describes the conditions for undertaking clinical trials of porcine islet products in TID.

7. Shapiro AM, Ricordi C, Hering BJ, Auchincloss H, Lindblad R, Robertson RP, et al. International trial of the Edmonton protocol for islet transplantation. N Engl J Med. 2006;355(13):01318-30.

8. Hogan A, Pileggi A, Ricordi C. Transplantation: current developments and future directions; the future of clinical islet transplantation as a cure for diabetes. Front Biosci. 2008;13:1192-205.

9. Pambianco G, Costacou T, Ellis D, Becker DJ, Klein R, Orchard TJ. The30-yearnatural history of type 1 diabetes complications: the Pittsburgh Epidemiology of Diabetes Complications Study experience. Diabetes. 2006;55(5):1463-9.

10. Prabhakaran S, Hering BJ. What strain of pig should be used? Xenotransplantation. 2008;15:83.

11. Koulmanda M, Qipo A, Smith RN, Auchincloss Jr H. Pig islet xenografts are resistant to autoimmune destruction by non-obese diabetic recipients after anti-CD4 treatment. Xenotransplantation. 2003;10(2):178-84.

12. Appel MC, Banuelos SJ, Greiner DL, Shultz LD, Mordes JP, Rossini AA. Prolonged survival of neonatal porcine islet xenografts in mice treated with a donor-specific transfusion and anti-CD154 antibody. Transplantation. 2004;77(9):1341-9.

13. Rood PP, Bottino R, Balamurugan AN, et al. Reduction of early graft loss after intraportal porcine islet transplantation in monkeys. Transplantation. 2007;83:202-10.

14. Morsiani E, Fogli L, Lanza Jr G, et al. Long-term insulin independence following repeated islet transplantation in totally pancreatectomized diabetic pigs. Cell Transplant. 2002;11:55-66.

15. - van der Windt DJ, Bottino R, Casu A, Campanile N, Smetanka $\mathrm{C}, \mathrm{He} \mathrm{J}$, et al. Long-term controlled normoglycemia in diabetic non-human primates after transplantation with hCD46 transgenic porcine islets. Am J Transplant. 2009;12:2716-26. This paper shows successful islet xenoTx in diabetic NHPs and, in particular, one transplanted diabetic monkey that remained exogenous insulin-free for more than 1 year.

16. Cardona K, Korbutt GS, Milas Z, et al. Long-term survival of neonatal porcine islets in nonhuman primates by targeting costimulation pathways. Nat Med. 2006;12:304-6.

17. Hering BJ, Wijkstrom M, Graham ML, et al. Prolonged diabetes reversal after intraportal xenotransplantation of wild-type porcine islets in immunosuppressed nonhuman primates. Nat Med. 2006;12:301-3.

18. Ricordi C, Finke EH, Lacy PE. A method for the mass isolation of islets from the adult pig pancreas. Diabetes. 1986;35:649-53.

19. Mandel TE. Fetal islet xenotransplantation in rodents and primates. J Mol Med. 1999;77:155-60.

20. Sandler S, Andersson A, Eizirik DL, et al. Assessment of insulin secretion in vitro from microencapsulated fetal porcine islet-like cell clusters and rat, mouse, and human pancreatic islets. Transplantation. 1997;63:1712. 
21. Hawthorne WJ, Simond DM, Stokes R, Patel AT, Walters S, Burgess $J$, et al. Subcapsular fetal pig pancreas fragment transplantation provides normal blood glucose control in a preclinical model of diabetes. Transplantation. 2011;91:515-21.

22. Hardikar AA, Wang XY, Williams LJ, Kwok J, Wong R, Yao M, et al. Functional maturation of fetal porcine beta-cells by glucagonlike peptide 1 and cholecystokinin. Endocrinology. 2002;143:350514.

23. Bennet W, Björkland A, Sundberg B, Davies H, Liu J, Holgersson $\mathrm{J}$, et al. A comparison of fetal and adult porcine islets with regard to Gal alpha $(1,3) \mathrm{Gal}$ expression and the role of human immunoglobulins and complement in islet cell cytotoxicity. Transplantation. 2000;69:1711-7.

24. Korbutt GS, Elliott JF, Ao Z, et al. Large scale isolation, growth, and function of porcine neonatal islet cells. J Clin Invest. 1996;97:2119-29.

25. Vizzardelli C, Molano RD, Pileggi A, Berney T, Cattan P, Fenjves ES, et al. Neonatal porcine pancreatic cell clusters as a potential source for transplantation in humans: characterization of proliferation, apoptosis, xenoantigen expression and gene delivery with recombinant AAV. Xenotransplantation. 2002;9:14-24.

26. Collares-Buzato CB, Leite AR, Boschero AC. Modulation of gap and adherens junctional proteins in cultured neonatal pancreatic islets. Pancreas. 2001;23:177-85.

27. Bottino R, Balamurugan AN, Smetanka $\mathrm{C}$, et al. Isolation outcome and functional characteristics of young and adult pig pancreatic islets for transplantation studies. Xenotransplantation. 2007; $14: 74-82$.

28. Dufrane D, D'Hoore W, Goebbels RM, et al. Parameters favouring successful adult pig islet isolations for xenotransplantation in pig-toprimate models. Xenotransplantation. 2006;13:204-14.

29. Yonekawa Y, Matsumoto S, Okitsu T, et al. Effective islet isolation method with extremely high islet yields from adult pigs. Cell Transplant. 2005;14:757-62.

30. Echeverri GJ, McGrath K, Bottino R, Hara H, Dons EM, van der Windt DJ, et al. Endoscopic Gastric Submucosal Transplantation of Islets (ENDO-STI): technique and initial results in diabetic pigs. Am J Transplant. 2009;9:2485-96.

31. Toso C, Brandhorst D, Oberholzer J, Triponez F, Buhler L, Morel P. Isolation of adult porcine islets of Langerhans. Cell Transplant. 2000;9:297-305.

32. Humphrey RK, Smith MS, Kwok J, Si Z, Tuch BE, Simpson AM. In vitro dedifferentiation of fetal porcine pancreatic tissue prior to transplantation as islet-like cell clusters. Cells Tissues Organs. 2001;168:158-69.

33. Wagner JD, Carlson CS, O'Brien TD, et al. Diabetes mellitus and islet amyloidosis in cynomolgus monkeys. Lab Anim Sci. 1996;46:36-41.

34. Szkudelski T. The mechanism of alloxan and streptozo- tocin action in B cells of the rat pancreas. Physiol Res. 2001;50:537-46.

35. Theriault BR, Thistlethwaite Jr JR, Levisetti MG, Wardrip CL, Szot G, Bruce DS, et al. Induction, maintenance, and reversal of streptozotocin-induced insulin-dependent diabetes mellitus in the juvenile cynomolgus monkey (Macaca fascilularis). Transplantation. 1999;68:331-7.

36. Bottino R, Criscimanna A, Casu A, He J, Van der Windt DJ, Rudert WA, et al. Recovery of endogenous $\beta$-cell function in nonhuman primates after chemical diabetes induction and islet transplantation. Diabetes. 2009;58:442-7.

37. Casu A, Bottino R, Balamurugan AN, Hara H, van der Windt DJ, Campanile N, et al. Metabolic aspects of pig-to-monkey (Macaca fascicularis) islet transplantation: implications for translation into clinical practice. Diabetologia. 2008;51:120-9.

38. Marigliano M, Casu A, Bertera S, Trucco M, Bottino R. Hemoglobin A1C percentage in Non-Human Primates: a useful tool to monitor diabetes before and after porcine pancreatic Islet Xenotransplantation. J Transplant. 2011;in press.

39. Buhler L, Deng S, O’Neil J, Kitamura H, Koulmanda M, Baldi A, et al. Adult porcine islet transplantation in baboons treated with conventional immunosuppression or a non-myeloablative regimen and CD154 blockade. Xenotransplantation. 2002;9:313.

40. Cantarovich D, Blancho G, Potiron N, Jugeau N, Fiche M, Chagneau $\mathrm{C}$, et al. Rapid failure of pig islet transplantation in non human primates. Xenotransplantation. 2002;9:25-35.

41. Rijkelijkhuizen JK, Haanstra KG, Wubben J, Tons A, Roos A, Gijlswijk-Janssen DJ, et al. T-cell-specific immunosuppression results in more than 53 days survival of porcine islets of Langerhans in the monkey. Transplantation. 2003;76:1359-68.

42. Kirchhof N, Shibata S, Wijkstrom M, Kulick DM, Salerno CT, Clemmings $\mathrm{S}$, et al. Reversal of diabetes in non-immunosuppressed rhesus macaques by intraportal porcine islet xenografts precedes acute cellular rejection. Xenotransplantation. 2004;11:396407.

43. Dufrane D, Goebbels RM, Saliez A, Guiot Y, Gianello P. Sixmonth survival of microencapsulated pig islets and alginate biocompatibility in primates: proof of concept. Transplantation. 2006;81:1345-53.

44. Komoda H, Miyagawa S, Omori T, Takahagi Y, Murakami H, Shigehisa T, et al. Survival of adult islet grafts from transgenic pigs with N-acetylglucosaminyl- transferase-III (GnT-III) in cynomolgus monkeys. Xenotransplantation. 2005;12(3):209-16.

45. Cardona K, Milas Z, Strobert E, Cano J, Jiang W, Safley SA, et al. Engraftment of adult porcine islet xenografts in diabetic nonhuman primates through targeting of costimulation pathways. Am J Transplant. 2007;7:2260-8.

46. Ayares D, Phelps C, Vaught T, Ball S. Genetic engineering of pigs for improved transplant outcomes. Xenotransplantation. 2007; 14:428.

47. Gianello P, Dufrane D. Encapsulation of pig islets by alginate matrix to correct streptozotocin-induced diabetes in primates without immunosuppression. Xenotransplantation. 2007;14:441.

48. Hecht G, Eventov-Friedman S, Rosen C, Shezen E, Tchorsh D, Aronovich A, et al. Embryonic pig pancreatic tissue for the treatment of diabetes in a nonhuman primate model. Proc Natl Acad Sci USA. 2009;106:8659-64.

49. •• Dufrane D, Goebbels RM, Gianello P. Alginate macroencapsulation of pig islets allows correction of streptozotocin-induced diabetes in primates up to 6 months without immunosuppression. Transplantation. 2010;90:1054-62. This paper assessed the capacity of alginateencapsulated islets to reverse diabetes in a pig-to-primate model up to 6 months even without immunosuppression.

50. Bennet W, Sundberg B, Groth CG, Brendel MD, Brandhorst D, Brandhorst $\mathrm{H}$, et al. Incompatibility between human blood and isolated islets of Langerhans: a finding with implications for clinical intraportal islet transplantation? Diabetes. 1999;48:1907-14.

51. van der Windt DJ, Bottino R, Casu A, Campanile N, Cooper DKC. Rapid loss of intraportally-transplanted islets:an overview of pathophysiology and preventive strategies. Xenotransplantation. 2007;14:288-97.

52. Ji M, Yi S, Smith-Hurst H, Phillips P, Wu J, Hawthorne W, et al. The importance of tissue factor expression by porcine NICC in triggering IBMIR in the xenograft setting. Transplantation. 2011;91:841-6.

53. Goto M, Tjernberg J, Dufrane D, et al. Dissecting the instant blood-mediated inflammatory reaction in islet xenotransplantation. Xenotransplantation. 2008;15:225-34.

54. Gangappa S, Larsen CP. Immunosuppressive protocols for pig-tohuman islet transplantation: lessons from pre-clinical non-human primate models. Xenotransplantation. 2008;15:107-11. 
55. Phelps CJ, Ball SF, Vaught TD, Vance AM, Mendicino M, Monahan $\mathrm{JA}$, et al. Production and characterization of transgenic pigs expressing porcine CTLA4-Ig. Xenotransplantation. 2009;16:477-85.

56. Gunji T, Saito T, Sato Y, Matsuyama S, Ise K, Kimura T, et al. Mitomycin-C treatment followed by culture produces long-term survival of islet xenografts in a rat-to mouse model. Cell Transplant. 2008;17:619-29.

57. Yun LD, Hee NJ, Byun Y. Functional and histological evaluation of transplanted pancreatic islets immunoprotected by PEGylation and cyclosporine for 1 year. Biomaterials. 2007;28:1957-66.
58. Ludwig B, Zimerman B, Steffen A, Yavriants K, Azarov D, Reichel A, et al. A novel device for islet transplantation providing immune protection and oxygen supply. Horm Metab Res. 2010;42:918-22.

59. Bloch K, Bloch O, Tarasenko I, Lazard D, Rapoport M, Vardi P. A strategy for the engineering of insulin producing cells with a broad spectrum of defense properties. Biomaterials. 2011;32:1816-25.

60. Ekser B, Cooper DKC. Overcoming the barriers to xenotransplantation: prospects for the future. Expert Rev Clin Immunol. 2010;6:219-30. 